\title{
Harnessing local ecological knowledge for conservation decision making via Wisdom of Crowds: the case of the Manus green tree snail Papustyla pulcherrima
}

\author{
N A THA N W H I M ORE
}

\begin{abstract}
The shell of the Manus green tree snail Papustyla pulcherrima is renowned for its beauty and is subject to international protection under CITES, having been harvested intensively in the past. To determine its threat status, and whether further conservation action is justified, an inexpensive Wisdom of Crowds approach was used to estimate the change in relative density of the snail between 1998 and 2013. Local men and women were approached around the main market on Manus Island, Papua New Guinea, and asked to map the relative abundance of the snail on an ordinal scale, based on their personal observations in 2013 and 1998 (a year of cultural significance). The spatial abundance data from 400 surveys were analysed using an information-theoretic approach. A suite of cumulative link models incorporating geographical factors was used to determine the magnitude of the change and to investigate possible biological influences underpinning the reported pattern. High abundance of the snail was associated with intact forested areas, high elevation and low population density. A slow decline was evident, with the median percentage of map cells where the snail was categorized as plentiful decreasing by c. $20 \%$ between the 2 years. On this basis a categorization of Near Threatened was advocated for the species. Although it is arguable that Wisdom of Crowds methods cannot be substituted for in situ quantification, the approach appears to have utility as a preliminary assessment for further conservation expenditure, and as a tool for determining threat status.
\end{abstract}

Keywords Cumulative link model, Data Deficient, decision making, local ecological knowledge, Papustyla pulcherrima, threat status, triage, Wisdom of Crowds

\section{Introduction}

$\mathrm{D}$ uring the past 2 decades increasing attention has been given to triage methods to prioritize species for

Nathan Whitmore Wildlife Conservation Society, Papua New Guinea Programme, P.O. Box 277, Goroka, Eastern Highlands Province, Papua New Guinea. E-mail nwhitmore@wcs.org

Received 17 November 2014. Revision requested 16 March 2015. Accepted 13 April 2015. First published online 7 August 2015. conservation intervention (e.g. Weitzman, 1998; Bottrill et al., 2008; Wilson et al., 2011). Implicit in such methods is an understanding of the level of crisis and the related drivers affecting the species in question. However, such threat assessments incur costs, and in the case of poorly understood or cryptic species, such as invertebrates, the cost of even a superficial in situ assessment may exceed the funding available.

Species-specific conservation programmes predominantly target vertebrates, with only a small fraction of the available funding being assigned to invertebrate conservation (Lydeard et al., 2004; Cardoso et al., 2011). Whereas most vertebrates have been categorized on the IUCN Red List (IUCN, 2014), $<0.5 \%$ of all described arthropods and $<4 \%$ of all described molluscs have been categorized (Cardoso et al., 2011). Given the scarcity of funding for invertebrate conservation, there is a need to allocate available funds in a prudent manner.

Researchers, especially in fisheries, are recognizing the potential of local ecological knowledge to address knowledge gaps regarding the status of natural resources and their management (e.g. Dulvy \& Polunin, 2004; SáenzArroyo et al., 2005; Arlinghaus \& Krause, 2013; Cano \& Tellería, 2013). Assessing such knowledge using a Wisdom of Crowds methodology is one potential way to produce cost-efficient estimates for threat status assignment and triage assessments. Wisdom of Crowds is a mechanism by which the aggregated knowledge of a large number of individuals is used to generate quantitative estimates. It was demonstrated over a century ago by Francis Galton (Galton, 1907), and popularized as a named concept by Surowiecki (2004). By aggregating information from a large sample population the idiosyncratic noise of individuals is diminished (Welsh, 2012). Often the resulting estimate, including those of quantity estimation and spatial reasoning, has been shown to be surprisingly accurate (Galton, 1907; Surowiecki, 2004; Arlinghaus \& Krause, 2013).

Surowiecki (2004) outlined four basic criteria for Wisdom of Crowds, which can be summarized as (1) diversity of opinion (i.e. individual interpretations are not censored), (2) independence (i.e. the opinion of an individual is not influenced by others), (3) decentralization (i.e. individuals are able to draw conclusions based on their local knowledge), and (4) aggregation (i.e. there is a mechanism for translating private judgements into a collective estimate). 
Although the application of the methodology is relatively new, Wisdom of Crowds is being investigated in a variety of fields, including politics (e.g. Bosler \& Schneider, 2011), economics (Nofer \& Hinz, 2014), computer science (e.g. Welinder et al., 2010) and sociology (Lorenz et al., 2011). Although it has been proposed as a mechanism to assist the management of fisheries in data-poor situations (Arlinghaus \& Krause, 2013), it has yet to become an established research method underpinning conservation and natural resource management initiatives.

The Manus green tree snail Papustyla pulcherrima is a forest-dwelling arboreal snail found only on Manus Island, a $1,900 \mathrm{~km}^{2}$ densely forested island to the north of Papua New Guinea. Its conical, emerald green shell, with a fine yellow border to the whorl, and a white lip, attains a maximum length of $4 \mathrm{~cm}$ and is renowned for its beauty (Pitman, 1977). After the snail's existence was popularized internationally in the 1930s demand for its shell grew, particularly for jewellery, which resulted in the export of large numbers of shells, and concerns about possible extinction of the species (Pitman, 1977). This resulted in the snail being the first invertebrate to be listed on the Endangered Species Act of 1973 (U.S. Government, 2003). International trade has been controlled by export permit since 1975 under CITES Appendix II (UNEP-WCMC, 2011) but the snail still faces potential threats from overexploitation for legal domestic trade (with the shells used for adornment), and habitat loss (Shearman et al., 2008, estimated that c. $32 \%$ of the forest on Manus Island had been cleared or degraded during 1972-2002). As of May 2015 the snail was still categorized as Data Deficient on the IUCN Red List (Mollusc Specialist Group, 1996), with its extinction risk unclear.

The majority of resident Manusians are indigenous and retain a subsistence lifestyle (Hide et al., 2002), and thus represent a repository of local ecological knowledge. The objective of this study was to utilize a Wisdom of Crowds approach to local ecological knowledge to ascertain temporal changes in the distribution and relative abundance of the Manus green tree snail, assess the need for further conservation efforts, and explore the utility of the Wisdom of Crowds technique.

\section{Study area}

The study took place in Lorengau, the provincial capital of Manus Province, and the only major town on the island of Manus, Papua New Guinea (Fig. 1). Surveys were carried out in and around the central covered market, which operated daily. This location was chosen because of the opportunity to survey people from diverse locations across Manus Island and the neighbouring offshore islands. As such, it was deemed to be broadly cross-sectional and representative of the wider community.

\section{Methods}

NW and four community facilitators (local Manusian staff trained in community engagement and conservation) surveyed adult market-goers, stall holders and local residents at random during 18-27 September 2013 (in a manner in accordance with the ethical standards of the British Sociological Association). The survey began 2 days after Papua New Guinea Independence Day, and market activity appeared to be typical over the survey period.

Each respondent was given two maps of Manus Island and adjacent islands, overlain with an indexed grid of 1,080 4- $\mathrm{km}^{2}$ map cells marked with village aid posts, townships and roads. Respondents were asked to mark map cells in which they had observed and were confident of the abundance of Manus green tree snails, using a five-point ordinal scale: (1) not found, (2) previously found but now absent, (3) scarce, (4) moderate numbers, (5) plentiful. Community facilitators assisted with interpretation of the map and completion of a form. On one map respondents recorded their observations of snail distribution and abundance in 2013, and on the other they recorded the same information based on their recollections from 1998 (the World Sea Kayaking Championships were held at Manus Island in 1998, and therefore this year had special significance in local memory). Only respondents that were 18 years or older in 1998 were asked to complete the 1998 map. Sites of known extinction were differentiated from sites of natural absence (e.g. because of habitat preference), but for purposes of modelling between years a single category representing absence was used. Unless the surveyor understood the local language of the respondent (there are 32 indigenous languages spoken in Manus Province) interviews were conducted in Tok Pisin.

Name, age, sex and home village were recorded for each respondent, as well as the name of the snail in their local language. All maps were checked for mistakes associated with duplication (for people with the same name), age threshold, and form-filling, and indications of influence or interference by a third party. There is no recommended threshold for the sample size required for Wisdom of Crowds methods but basic principles suggest that the sample should be sufficiently large to diminish idiosyncratic noise. I estimated we would need a minimum sample size of 300 respondents, and aimed to maximize the sample within the constraints of our budget. We conducted a total of 423 surveys, of which 400 were deemed valid following exclusions for third-party interference, duplication, and incomplete forms.

In addition to the mapping exercise 59 structured interviews with open-ended questions were used to gather qualitative information on aspects of the snail's life history, commercial value and temporal population trends from a random subsample of the respondents (pertinent metadata are reported here). To estimate the sales turnover from 


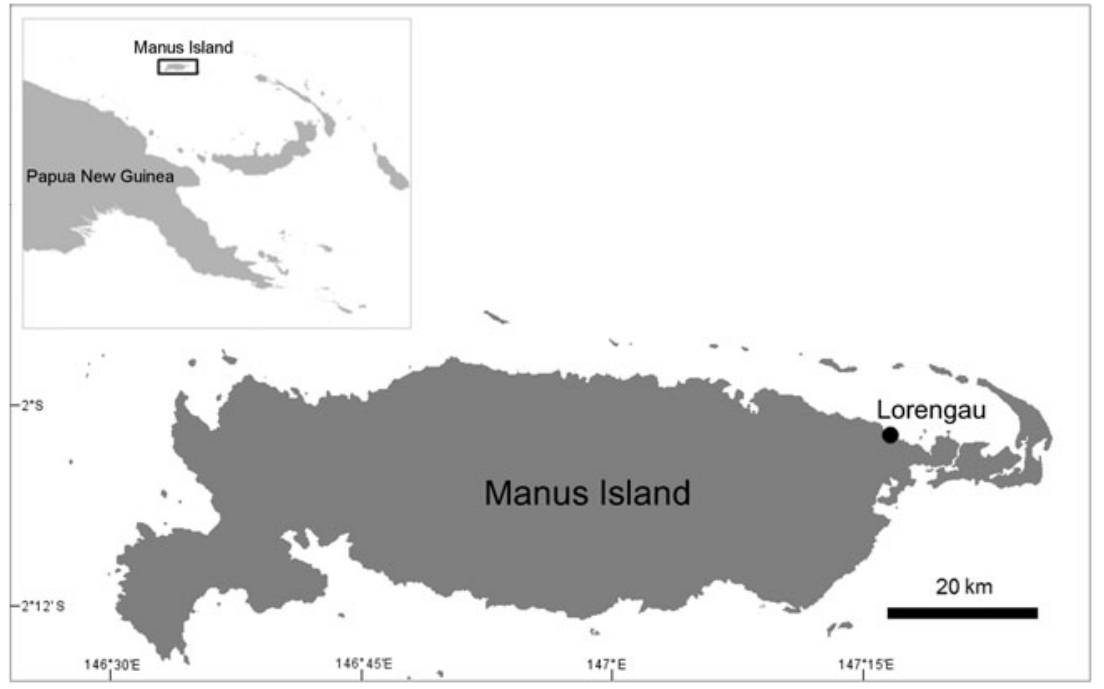

FIG. 1 Manus Island, Papua New Guinea, where surveys were carried out in the town of Lorengau. snail shells, a community facilitator recorded the number of shells on sale and sold each day during 22-27 September 2013.

Data analysis was carried out in $R$ v.3.o (R Development Core Team, 2013), with additional functionality provided by various packages. Geographical forest cover data (percentage tree cover in 2000; losses and gains during 2000-2012) were sourced from Global Forest Change tagged image files (TIFs) derived from Landsat data (Hansen et al., 2013), and altitude data for Manus Province were sourced from the Papua New Guinea Resource Information System as MAPInfo files (Bryan \& Shearman, 2007). Both datasets were converted into raster maps, in the Universal Transverse Mercator projection, in $R$ using the package raster (Hijmans, 2013) in conjunction with rgdal (Bivand et al., 2013), and aggregated to the same resolution as the snail survey grid. Forest change data were converted into two layers, representing 2000 and 2012 coverage. The raster values corresponding to the non-empty survey map cells were collated to form covariates within a single data frame.

The ordinal data were analysed using cumulative link models (also known as ordered logit regression). The response variable from such models represents the accumulated log-odds of occurrence in or below a particular ordinal abundance category (Agresti, 2010), and can be used to calculate the predicted probabilities for each ordinal abundance category in each of the 1,080 map cells.

Six explanatory variables were considered in the models: altitude, forest cover, sample, biogeography, period and surveyor. Altitude (alt) was a continuous variable, measured in metres. Forest cover (forestcov) was the canopy cover in 2000 and 2012, used as proxies for cover in 1998 and 2013, respectively (which was not available from the Hansen et al., 2013, dataset), and was assigned a value between o (no cover) and 1 (100\% cover). Sample (sample) was the number of times a grid cell was reported on; it was considered to be a proxy of human population density. Biogeography (biog) was a categorical variable representing mainland or offshore islands (for the purposes of this study the island of Los Negros, which is separated from Manus Island by a narrow body of water, Lonui Passage, was considered to be part of the mainland). Surveyor (surveyor) represented the individual effect of each interviewer. Period (period) represented a time effect distinguishing the year under assessment (1998 or 2013). Nineteen candidate cumulative link models were created using combinations of these explanatory variables, and tested using the package ordinal (Christensen, 2013). A deliberately poor model (based on a singular intercept) was run within the suite of candidate models to represent a baseline for poor performance.

This suite of 20 candidate models was assessed in an information-theoretic model testing framework (sensu Burnham \& Anderson, 2002) using the package AICcmodavg (Mazerolle, 2013). Predicted values for the top model (lowest Akaike information criterion with a small sample correction, AICc) were calculated using the package MASS (Venables \& Ripley, 2002). Based on a priori knowledge I expected that the model coefficients would be positive for forestcov and alt, and negative for period (i.e. declining) and sample (i.e. inversely proportional to reporting density); I had no particular expectations for biog and surveyor effects.

\section{Results}

The cells reported on by respondents broadly reflected the known pattern of human population distribution (Fig. 2): cells in the east of the island were heavily reported on, whereas elsewhere reports were primarily from areas around 


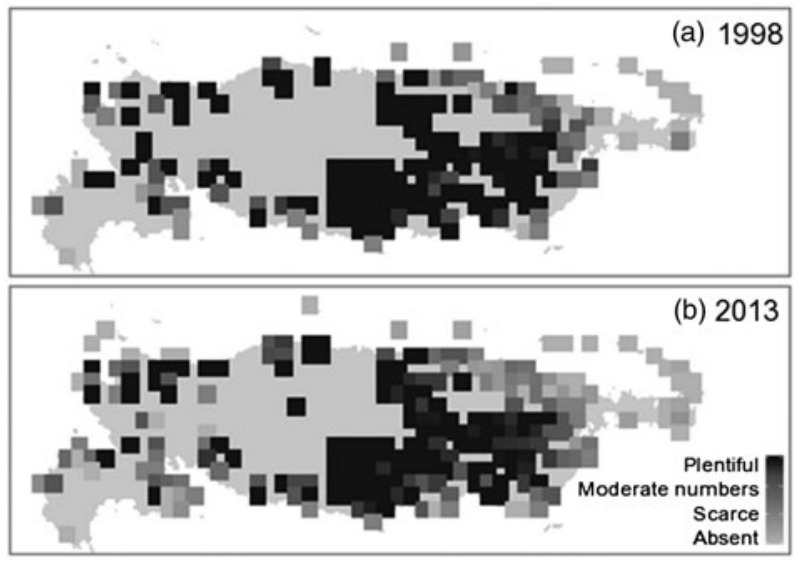

FIG. 2 Visualization of Manus green tree snail Papustyla pulcherrima abundance on Manus Island (Fig. 1) as reported for 1998 and 2013. Cell colouration depicts abundance as a continuous variable, under the assumption of equal distance between ordinal abundance categories.

coastal villages, and were most sparse in the vicinity of the central forest. Thus, unreported and less frequently reported grids probably coincide with areas less affected by human activities.

The top model was the most highly parameterized model (period + alt + forestcov + biog + sample + surveyor $; 12$ parameters) and had considerable support (model weight $=93 \%$; Table 1). Only one of the other candidate models had any support: period + alt + forestcov + biog + surveyor (model weight $=7 \%$ ). The most important parameters in the top model, in terms of magnitude, given the range of covariates were alt and forestcov (Table 2).

The parameter period indicated that relative abundance was consistently lower in 2013 than in 1998 (Table 2). The support for the surveyor parameter in the top model (Table 1) and the relatively high surveyor coefficients (Table 2) indicate that respondents' replies were influenced by the surveyor. A comparison of the top model with and without the surveyor parameter, however, resulted in a comparatively minor change in the estimation of the period parameter (with: -0.6198 ; without: -0.5782 ), which suggests that regardless of variation between surveyors, the effect of period was real. When converted into an odds ratio the period effect coefficient estimated that the map cells were $35 \%$ more likely to be assessed in a lower ordinal category in 2013 than in 1998.

The predicted probability for any given map cell $Y$ occurring in an ordinal abundance category $j$ (or below) could be calculated from the coefficients of the top model (Table 2):

$P(Y \leq j)$

$=\frac{\exp \left(\alpha_{j}-\beta_{1} \text { period }-\beta_{2} \text { alt }-\beta_{3} \text { forestcov }-\beta_{4} \text { biog }-\beta_{5} \text { sample }-\beta_{6} \text { surveyor }\right)}{1+\exp \left(\alpha_{j}-\beta_{1} \text { period }-\beta_{2} \text { alt }-\beta_{3} \text { forestcov }-\beta_{4} \text { biog }-\beta_{5} \text { sample }-\beta_{6} \text { surveyor }\right)}$

When the predicted values for the top model were examined between time periods the magnitude of the change in relative abundance could be seen as a difference in the probability of assignment between ordinal abundance categories (Fig. 3). It was apparent that the probability of a cell being assigned the highest ordinal abundance category (i.e. plentiful) declined between 1998 and 2013 and the probability that a cell would be assigned a lower category increased (Fig. 3). A comparison of medians of the plentiful category suggested a decline from $89 \%$ of map cells in 1998 to $71 \%$ in 2013.

Among the 59 respondents to the structured interviews there was a high rate of concurrence regarding where and when the snails could be found feeding (Table 3). There was marginally more support for the perception that the snail population was increasing rather than decreasing. Thirty-seven percent of respondents claimed they could identify the sex of the snails, although members of the family Camaenidae are known to be hermaphroditic (Jordaens et al., 2007). Over half of the interviewees reported selling shells at some time.

Of 399 shells for sale at the Lorengau market over a 5-day period, 79 were sold, by seven vendors. Of these, 56 were bought by a local hotel, presumably to replenish their stock on sale for tourists. The asking price was determined by size: PGK 1 for small shells and PGK 1.50 for large shells (equivalent to USD 0.40 and 0.60 , respectively). One vendor specialized in snail shell jewellery and sold a variety of necklaces and earrings for PGK 10-20 (equivalent to USD 4 and 8 ). He claimed to sell 20-30 items per week.

\section{Discussion}

The results of the Wisdom of Crowds method show congruity with my a priori expectations of model coefficient direction: positive for forest cover and altitude, and negative for period and sample reporting (as a proxy for human population distribution). The support for the inclusion of multiple environmental parameters, developed a priori through preliminary knowledge of the snail's biology and immediate threats, raises confidence that the respondents' reports have a reasonable ecological basis. Within the suite of models there was preferential support for the inclusion of the parameter period (which appears in the top two models and accounts for $100 \%$ of model weight support). This indicates there was an additional effect (a decline) in the response that was not accounted for by my choice of environmental variables. The cause of the underlying decline is unclear; likely candidates include harvesting pressure and environmental effects (e.g. climatic change) but psychological effects (e.g. people remembering the past being better than it was) cannot be ruled out.

Cumulative link models can show the magnitude of change on a relative scale but describing an absolute change 
TABLE 1 Candidate models for the prediction of ordinal categories, with number of parameters, Akaike's information criterion with a small sample correction (AICc), $\triangle \mathrm{AICc}$, model weight, cumulative model weight, and maximized value of the log-likelihood function (LL). The models are ranked by AICc.

\begin{tabular}{|c|c|c|c|c|c|c|c|}
\hline Rank & Model & No. of parameters & AICc & $\Delta \mathrm{AICc}^{*}$ & $\begin{array}{l}\text { Model } \\
\text { weight }\end{array}$ & $\begin{array}{l}\text { Cumulative } \\
\text { weight }\end{array}$ & $\mathrm{LL}$ \\
\hline 1 & period + alt + forestcov + biog + sample + surveyor & 12 & $2,182.05$ & 0 & 0.93 & 0.93 & $-1,078.92$ \\
\hline 2 & period + alt + forestco $v+$ biog + surveyor & 11 & $2,187.15$ & 5.1 & 0.07 & 1 & $-1,082.49$ \\
\hline 3 & alt + forestcov + biog + sample + surveyor & 11 & $2,200.48$ & 18.43 & 0 & 1 & $-1,089.15$ \\
\hline 4 & alt + forestcov + biog + surveyor & 10 & $2,211.31$ & 29.25 & 0 & 1 & $-1,095.58$ \\
\hline 5 & period + alt + forestcov + biog + sample & 8 & $2,220.21$ & 38.16 & 0 & 1 & $-1,102.06$ \\
\hline 6 & period + alt + forestco $v+$ biog & 7 & $2,224.11$ & 42.05 & 0 & 1 & $-1,105.02$ \\
\hline 7 & period + alt + forestcov & 6 & $2,224.21$ & 42.16 & 0 & 1 & $-1,106.08$ \\
\hline 8 & alt + forestcov + biog + sample & 7 & $2,237.02$ & 54.97 & 0 & 1 & $-1,111.47$ \\
\hline 9 & $a l t+$ forestcov + biog & 6 & $2,245.56$ & 63.51 & 0 & 1 & $-1,116.75$ \\
\hline 10 & alt + forestcov & 5 & $2,245.99$ & 63.94 & 0 & 1 & $-1,117.98$ \\
\hline 11 & $a l t+$ biog + surveyor & 9 & $2,309.84$ & 127.79 & 0 & 1 & $-1,145.86$ \\
\hline 12 & period + alt + biog & 6 & $2,313.21$ & 131.16 & 0 & 1 & $-1,150.58$ \\
\hline 13 & period + alt & 5 & $2,324.78$ & 142.72 & 0 & 1 & $-1,157.37$ \\
\hline 14 & $a l t+b i o g$ & 5 & $2,339.19$ & 157.14 & 0 & 1 & $-1,164.58$ \\
\hline 15 & alt & 4 & $2,350.55$ & 168.5 & 0 & 1 & $-1,171.26$ \\
\hline 16 & forestcov & 4 & $2,536.46$ & 354.4 & 0 & 1 & $-1,264.21$ \\
\hline 17 & period + sample & 5 & $2,831.03$ & 648.97 & 0 & 1 & $-1,410.49$ \\
\hline 18 & sample & 4 & $2,875.53$ & 693.48 & 0 & 1 & $-1,433.75$ \\
\hline 19 & period & 4 & $2,904.46$ & 722.41 & 0 & 1 & $-1,448.22$ \\
\hline 20 & Singular intercept & 3 & $2,935.74$ & 753.69 & 0 & 1 & $-1,464.86$ \\
\hline
\end{tabular}

${ }^{*}$ Difference between the AICc of the current model and the top model

cannot be undertaken unless equality of distance between the ordinal categories is assumed. Although this assumption may be helpful for visualization (especially mapping; e.g. Fig. 2) there is no logical basis for its application. However, model predictions of the probability of assignment to each ordinal abundance category can clarify the magnitude of the change. These predictions show that the probability of the snail being assigned to the plentiful category declined from 1998 to 2013 , with a compensatory increase in the probability of all the other categories (Fig. 3). For both years the majority of responses fell in the plentiful category, with the predicted probability declining from 89 to $71 \%$ between 1998 and 2013 .

The modelling suggested that respondents were influenced by the surveyor. It is likely that each surveyor's individual manner and phrasing influenced respondents in their interpretations of where the transition points between relative abundance categories lay. Although the inclusion of a surveyor effect in the top model caused little change to the period coefficient estimate, it caused the estimated qualitative decline to increase from c. 15 to c. $20 \%$ over the 15 -year period. I used the higher figure in a precautionary approach but am aware that the difference is probably an artefact and indicates greater measures to ensure surveyor consistency should be undertaken in future.

Despite limited sales data collected from the Lorengau market, a crude extrapolation of shell sales over a 6-day period suggests that annual sales may approach 5,000. From the interviews it was apparent that some shells were being traded internationally, despite the restrictions on international trade. One interviewee reported giving 400 shells to a relative for sale in Australia; another market vendor reported an expatriate buying her entire stock of 32 shells for PGK 5 per shell (five times the standard price). Based on these anecdotes it is conceivable that the number of shells being supplied internationally may approach or eclipse the domestic trade.

Online searches revealed the shells were being sold, often as antiques, in open forums and internet market places based in New Zealand, Australia and the USA. The majority of listings avoided using the common name or a variant, instead referring to the snails simply as land snails, and using the antiquated scientific pseudonym Papuina pulcherrima rather than Papustyla pulcherrima. The avoidance of conventional nomenclature may be an attempt to avoid detection by authorities. In some cases sellers in internet market places were based in CITES member countries (including Australia, Italy, New Zealand, Singapore and USA). The quantity of shells for sale in such online market places appears to be low, suggesting that the existing controls on international trade may be adequate. However, given that the prices of shells for sale online were often orders of magnitude greater than market prices on Manus Island, vigilance will be required to ensure that illegal international demand does not fuel a resurgence in snail collection.

As of May 2015 the Manus green tree snail was categorized as Data Deficient (Mollusc Specialist Group, 1996). 
TABLE 2 Coefficients for the prediction of ordinal categories, based on the top model (period + alt + forestcov + biog + sample + surveyor $)$, with estimates on the logit scale, and range of covariates.

\begin{tabular}{lrl}
\hline & Estimate \pm SE & Covariate range \\
\hline $\boldsymbol{\alpha}_{\boldsymbol{j}}$ threshold coefficients & & \\
Absent/scarce & $1.0612 \pm 0.3349$ & \\
Few/moderate & $2.1308 \pm 0.3445$ & \\
Moderate/plentiful & $2.7233 \pm 0.3483$ & \\
$\boldsymbol{\beta}_{\boldsymbol{n}}$ coefficients & & \\
Period (2013) & $0.6198 \pm 0.1386$ & 0 or 1 \\
Alt & $0.0201 \pm 0.0016$ & $0-435$ \\
Forestcov & $3.5588 \pm 0.3788$ & $0.009-0.970$ \\
Biog (offshore island) & $0.4023 \pm 0.3595$ & 0 or 1 \\
Sample & $-0.0423 \pm 0.0158$ & $1-22$ \\
Surveyor & & \\
$\quad$ Person 1 & $0.0267 \pm 0.1998$ & \\
$\quad$ Person 2 & $-0.6301 \pm 0.1697$ & \\
$\quad$ Person 3 & $0.0082 \pm 0.5269$ & \\
$\quad$ Person 4 & $0.5805 \pm 0.1855$ & \\
\hline
\end{tabular}

IUCN guidelines specify that assessors should, where possible, refrain from assigning this category where habitat deterioration and other causal factors are known (IUCN, 2013). This study provided two pieces of information to facilitate categorization of the snail: (1) a qualitative decline of c. $20 \%$ over 15 years, and (2) the positive relationship between forest cover and snail abundance.

If the qualitative rate of decline is assumed to be equivalent to an absolute change (a worst case scenario) it is still less than the threshold of $\geq 30 \%$ decline over 10 years or three generations required by IUCN for a categorization of Vulnerable under criterion A (IUCN, 2013). Of the remaining assessment criteria, the snail appears to come closest to attaining a Vulnerable categorization under criterion B (i.e. continuing decline) but fails to meet the threshold because the population is neither highly fragmented nor subject to extreme fluctuations. On this basis a petition was made to the IUCN, and our recommended categorization of Near Threatened was accepted and was conferred in version 2015.2 of the Red List (Whitmore et al., 2015). We informed the Manus provincial government of this development. However, forest clearance is an ongoing threat on Manus Island, with proposed logging, mining, road building and agroforestry developments (Wildlife Conservation Society, unpubl. data). If large-scale deforestation were to occur, a review of the snail's threat status would be advisable.

The results suggest that the Manus green tree snail does not require immediate in situ conservation intervention, despite the threats outlined. According to the Red List (IUCN, 2014) there are other species on Manus Island facing a greater risk of extinction. In the short term, therefore, it is proposed there should be no further conservation expenditure on this snail species per se but that conservation of this and other species on the island is likely to be served best by focusing on the

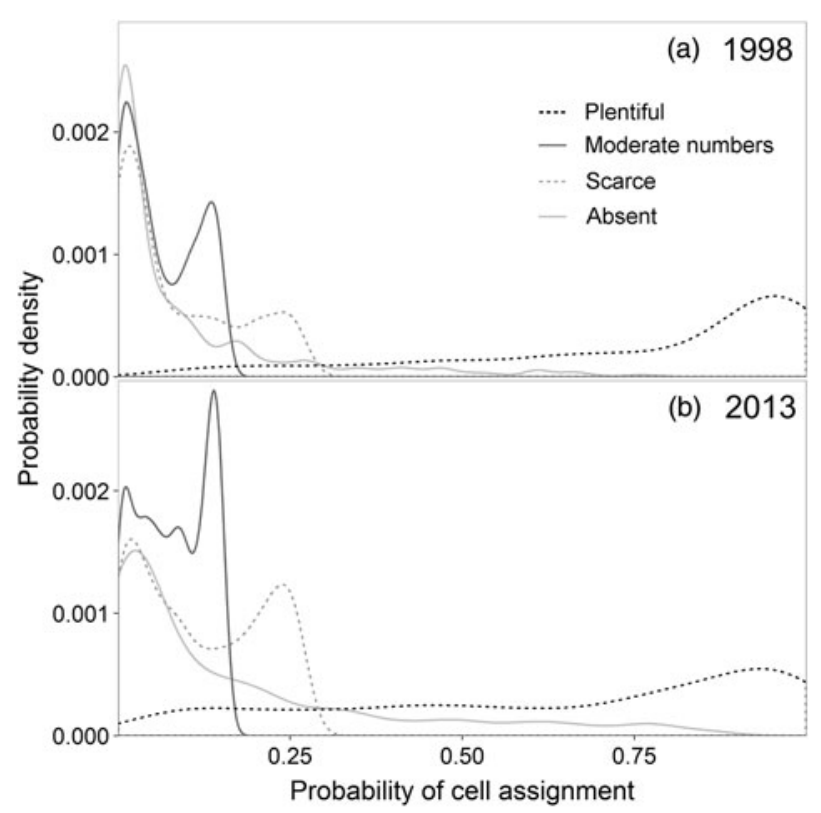

FIG. 3 A comparison of the predicted probability of assignment to each ordinal abundance category for 1998 and 2013 on the basis of the top model

(period + alt + forestcov + biog + sample + surveyor $)$.

protection of the remaining primary forest, which covers much of central Manus. Specific interventions for the Manus green tree snail are unlikely to be necessary at present but we are trying to raise awareness among the public, tourists, provincial government, and the relevant customs agencies of its CITES II status and the repercussions of illegal international trade.

It is important to note that this work does not advocate the use of Wisdom of Crowds methods to supplant quantitative field monitoring. Well-structured quantitative monitoring (sensu Lindenmayer \& Likens, 2010) remains the ideal. However, Wisdom of Crowds methods are probably sufficient for basic conservation decision making, such as determining a species' threat status or undertaking a triage assessment in circumstances where there is local knowledge of the resource or species in question and a large sample size can be acquired but a quantitative survey is not possible because of financial constraints. For these reasons Wisdom of Crowds methods may be of particular utility in rural areas in the developing world.

Describing resource change based on personal or collective memory unavoidably raises questions about how people perceive and recall environmental change. Papworth et al. (2009) proposed two categories of possible memory artefacts: (1) personal amnesia, in which the respondent remembers past conditions inaccurately, and (2) generational amnesia, in which environmental baselines are reset with each passing generation because of a lack of intergenerational memory. In the case of personal amnesia, Wisdom of Crowds methods, as a consequence of their requirement for a large sample size, 
TABLE 3 Concurrence rate of information provided by 59 respondents in open structured interviews.

\begin{tabular}{lc}
\hline Information & \% interviewees concurring \\
\hline Snails feed on leaves or leaf biofilms. & 97 \\
The best time to search for snails is during early morning. & 73 \\
Snails are encountered most commonly after primary forest has been cleared for the establishment of gardens. & 54 \\
The respondent sells snail shells. & 52 \\
The snail population is stable or increasing. & 38 \\
The respondent could identify the sex of snails. & 37 \\
The respondent could not identify the sex of snails. & 36 \\
The snail population is stable or decreasing. & 32 \\
Snails are found on the leaves of the sago palm. & 29
\end{tabular}

should be capable of dampening idiosyncratic noise and discerning the underlying pattern if the errors in memory are highly individualized and random rather than skewed in nature. Although there was no clear evidence of generational amnesia in this study, c. 9\% of all respondents had no knowledge of the snail's name in their native language, which suggests some loss of cultural knowledge had taken place.

I suggest that prior to the application of Wisdom of Crowds an examination of what Palmer \& Wadley (2007) described as local ecological talk (i.e. what people say they know) is required. There is potential for confusion between local ecological talk and local ecological knowledge, which for the purposes of Wisdom of Crowds must be experiential in nature. Examples of this dichotomy can be seen in some of the answers to open interview questions. Questions that could be clarified by simple observation elicited a narrow range of near unanimous answers (e.g. 97\% mentioned that the snails fed on leaves and/or leaf biofilms), which could be considered local ecological knowledge. In contrast, the answers to the question of whether respondents could identify the sex of snails, and how, were equivocal and variable, suggesting this was an example of local ecological talk rather than knowledge. It is therefore advisable to use a Wisdom of Crowds approach only for questions that can be resolved by superficial observation (e.g. changes in spatial patterns and abundance), and not for matters of biology, which by their hidden nature are subject to conjecture and local ecological talk.

Although other researchers have advocated the use of local ecological knowledge to address questions regarding natural resources and their management (e.g. Huntington, 2000; Fazey et al., 2006; Raymond et al., 2010; Sutherland et al., 2014), much of the emphasis has been on the screening of local experts (e.g. Davis \& Wagner, 2003; Martin et al., 2012) and the development of group consensus, typically using a Delphi technique framework (e.g. van der Hoeven et al., 2004; Leite \& Gasalla, 2013). This essentially operates by allowing the opinion of independent experts to evolve through a series of iterative information feedback loops until a consensus is reached (Hsu \& Sandford, 2007). Wisdom of Crowds methods, by comparison, represent a substantial departure from this paradigm as there is no screening of expert panellists, nor information feedback systems, and the conclusion is reached statistically using a large sample size rather than by the consensus of a small group.

Given the need for cheap and rapid species assessment tools and the impetus for judicious use of conservation funds, Wisdom of Crowds methods are an overlooked but potentially valuable tool for conservation. For widespread acceptance of the Wisdom of Crowds methodology confirmatory field surveys will be required to validate the technique. Pragmatically, high-profile species, which have the potential to elicit reasonable levels of funding for comparative field surveys, will be the focus of such validation tests. In the long term, however, it is likely that Wisdom of Crowds methods will be used primarily in countries where conservation budgets are meagre, and focused on species for which opportunities to elicit funding are limited and for which conventional field survey methods are unaffordable.

\section{Acknowledgements}

This survey would not have been possible without the assistance of the Wildlife Conservation Society (WCS) Manus community facilitators: Heoa Itariri, Jenny Wak, Julien Benjamin and Pondrilei Sori. WCS staff members June Poloman, Daniel Charles, Lilly Ugi, Junior Walker, John Ole and Marygrace Wanamp-Puri provided logistical support for the project. I am grateful to Arison Arihafa, John Lamaris, Wallace Takendu, Mazzella Maniwavie, Sven Frijlink, Richard Cuthbert and two anonymous reviewers for their insightful feedback. This project was funded by The Christensen Foundation as part of a WCS project on nature and culture. I am grateful to the Manus Provincial Government for allowing this project to take place. I thank all the survey respondents in Lorengau for their patience and involvement in this study.

\section{References}

Agresti, A. (2010) Analysis of Ordinal Categorical Data. 2nd edition. John Wiley \& Sons Hoboken, USA. 
Arlinghaus, R. \& Krause, J. (2013) Wisdom of the crowd and natural resource management. Trends in Ecology \& Evolution, 28, 8-11.

Bivand, R., Keitt, T. \& Rowlingson, B. (2013) rgdal: Bindings for the Geospatial Data Abstraction Library. R v. o.8-11. Http://CRAN R-project.org/package $=$ rgdal [accessed 3 June 2015].

Bosler, N. \& Schneider, G. (2011) The oracle or the crowd? Experts versus the stock market in forecasting ceasefire success in the Levant. In Global Governance: Political Authority in Transition. International Studies Association Annual Conference. Montreal, Canada.

Bottrill, M.C., Joseph, L.N., Carwardine, J., Bode, M., Cook, C., GAmE, E.T. et al. (2008) Is conservation triage just smart decision making? Trends in Ecology \& Evolution, 23, 649-654.

Bryan, J.E. \& Shearman, P.L. (eds) (2007) Papua New Guinea Resource Information System Disks. PNGRIS Publication No. 7. University of Papua New Guinea, Port Moresby, Papua New Guinea.

Burnham, K.P. \& Anderson, D.R. (2002) Model Selection and Multimodel Inference: A Practical Information-Theoretic Approach. and edition. Springer-Verlag, New York, USA.

Cano, L.S. \& Tellería, J.L. (2013) Local ecological knowledge as a tool for assessing the status of threatened vertebrates: a case study in Vietnam. Oryx, 47, 177-183.

Cardoso, P., Erwin, T.L., Borges, P.A.V. \& New, T.R. (2011) The seven impediments in invertebrate conservation and how to overcome them. Biological Conservation, 144, 2647-2655.

Christensen, R.H.B. (2013) ordinal: Regression Models for Ordinal Data. $R$ v. 2013.9-30. Http://www.cran.r-project.org/package= ordinal [accessed 3 June 2015].

DAVIS, A. \& WAGNeR, J.R. (2003) Who knows? On the importance of identifying 'experts' when researching local ecological knowledge. Human Ecology, 31, 463-489.

Dulvy, N.K. \& Polunin, N.V.C. (2004) Using informal knowledge to infer human-induced rarity of a conspicuous reef fish. Animal Conservation, 7, 365-374.

Fazey, I., Fazey, J.A., SAlisbury, J.G., Lindenmayer, D.B. \& Dovers, S. (2006) The nature and role of experiential knowledge for environmental conservation. Environmental Conservation, 33, 1-10.

Galton, F. (1907) Vox populi. Nature, 75, 450-451.

Hansen, M.C., Potapov, P.V., Moore, R., Hancher, M., Turubanova, S.A., Tyukavina, A. et al. (2013) High-resolution global maps of 21st-century forest cover change. Science, 342, $850-853$.

Hide, R.L., Allen, B.J., Bourke, R.M., Fritsch, D., Grau, R., Helepet, J.L. et al. (2002) Manus Province: Text Summaries, Maps, Code Lists and Village Identification. Agricultural Systems of Papua New Guinea. Working Paper No 18. The Australian National University, Canberra, Australia.

Hijmans, R.J. (2013) raster: Geographic Data Analysis and Modeling. $R$ package v. 2.1-49. Http://CRAN.R-project.org/package=raster [accessed 3 June 2015].

Hsu, C.C. \& S AndFord, B.A. (2007) The Delphi technique: making sense of consensus. Practical Assessment, Research \& Evaluation, 12, $1-8$.

HUNTINGTON, H.P. (2000) Using traditional ecological knowledge in science: methods and applications. Ecological Applications, 10, 12701274 .

IUCN (2013) Guidelines for Using the IUCN Red List Categories and Criteria. Version 10. Standards and Petitions Subcommittee, IUCN, Gland, Switzerland.

IUCN (2014) IUCN Red List of Threatened Species v. 2014.2. Http:// www.iucnredlist.org [accessed 20 August 2014].
Jordaens, K., Dillen, L. \& Backeljau, T. (2007) Effects of mating, breeding system and parasites on reproduction in hermaphrodites: pulmonate gastropods (Mollusca). Animal Biology, 57, 137-195.

Leite, M.C. \& Gasalla, M.A. (2013) A method for assessing fishers' ecological knowledge as a practical tool for ecosystem-based fisheries management: seeking consensus in south-eastern Brazil. Fisheries Research, 145, 43-53.

Lindenmayer, D.B. \& Likens, G.E. (2010) Effective Ecological Monitoring. CSIRO Publishing, Collingwood, Australia.

Lorenz, J., Rauhut, H., Schweitzer, F. \& Helbing, D. (2011) How social influence can undermine the wisdom of crowd effect. Proceedings of the National Academy of Sciences, 108, 9020-9025.

Lydeard, C., Cowie, R.H., Ponder, W.F., Bogan, A.E., Bouchet, P., Clark, S.A. et al. (2004) The global decline of nonmarine mollusks. BioScience, 54, 321-330.

Martin, T.G., Burgman, M.A., Fidler, F., Kuhnert, P.M., Low-Choy, S., McBride, M. \& Mengersen, K. (2012) Eliciting expert knowledge in conservation science. Conservation Biology, 26, 29-38.

Mazerolle, M.J. (2013) AICcmodavg: Model Selection and Multimodel Inference Based on (Q)AIC(c). R v. 1.29. Http://CRAN. R-project.org/package $=$ AICcmodavg [accessed 3 June 2015].

Mollusc Specialist Group (1996) Papustyla pulcherrima. In The IUCN Red List of Threatened Species v.2014.2. Http://www. iucnredlist.org [accessed 8 August 2014].

Nofer, M. \& Hinz, O. (2014) Are crowds on the internet wiser than experts? The case of a stock prediction community. Journal of Business Economics, 84, 303-338.

Palmer, C.T. \& Wadley, R.L. (2007) Local environmental knowledge, talk, and skepticism: using 'LES' to distinguish 'LEK' from 'LET' in Newfoundland. Human Ecology, 35, 749-76o.

Papworth, S.K., Rist, J., CoAd, L. \& Milner-Gulland, E.J. (2009) Evidence for shifting baseline syndrome in conservation. Conservation Letters, 2, 93-100.

Pitman, R.W. (1977) Manus Island's green tree snails at home. Hawaiian Shell News, 15, 9-10.

Raymond, C.M., Fazey, I., Reed, M.S., Stringer, L.C., Robinson, G.M. \& Evely, A.C. (2010) Integrating local and scientific knowledge for environmental management. Journal of Environmental Management, 91, 1766-1777.

R Development Core Team (2013) R: A Language and Environment for Statistical Computing. R Foundation for Statistical Computing, Vienna, Austria.

Sáenz-Arroyo, A., Roberts, C.M., Torre, J. \& Cariño-Olvera, M. (2005) Using fishers' anecdotes, naturalists' observations and grey literature to reassess marine species at risk: the case of the Gulf grouper in the Gulf of California, Mexico. Fish and Fisheries, 6, $121-133$.

Shearman, P.L., Bryan, J.E., Ash, J., Hunnam, P., Mackey, B. \& Lokes, B. (2008) The State of the Forests of Papua New Guinea. Mapping the Extent and Condition of Forest Cover and Measuring the Drivers of Forest Change in the Period 1972-2002. University of Papua New Guinea, Port Moresby, Papua New Guinea.

Surowiecki, J. (2004) The Wisdom of Crowds: Why the Many Are Smarter Than the Few. Little Brown, London, UK.

Sutherland, W.J., Gardner, T.A., Haider, L.J. \& Dicks, L.V. (2014) How can local and traditional knowledge be effectively incorporated into international assessments? Oryx, 48, 1-2.

UNEP-WCMC (2011) Checklist of CITES Species (CD-ROM). CITES Secretariat, Geneva, Switzerland, and UNEP World Conservation Monitoring Centre, Cambridge, UK.

U.S. Government (2003) Endangered Species Act of 1973, As Amended Through the 108th Congress. Http://www.fws.gov/ endangered/esa-library/pdf/ESAall.pdf [accessed 3 June 2015]. 
van der Hoeven, C.A., De Boer, W.F. \& Prins, H.H. (2004) Pooling local expert opinions for estimating mammal densities in tropical rainforests. Journal for Nature Conservation, 12, 193-204.

Venables, W.N. \& Ripley, B.D. (2002) Modern Applied Statistics with $S$. 4 th edition. Springer, New York, USA.

Weitzman, M.L. (1998) The Noah's ark problem. Econometrica, 66, 1279-1298.

Welinder, P., Branson, S., Perona, P. \& Belongie, S.J. (2010) The multidimensional wisdom of crowds. In Advances in Neural Information Processing Systems 23: 24th Annual Conference on Neural Information Processing Systems 2010 (eds J.D. Lafferty \& C.K.I. Williams) pp. 2424-2432. Curran Associates Inc., Red Hook, USA.

Welsh, M.B. (2012) Expertise and the wisdom of crowds: whose judgments to trust and when. In Building Bridges Across Cognitive Sciences Around the World: Proceedings of the 34th Annual Meeting of the Cognitive Science Society, Sapporo, Japan, August 1-4, 2012 (eds N. Miyake, D. Peeble \& R.P. Cooper), pp. 1131-1136. Curran Associates Inc., Red Hook, USA.

Whitmore, N., Arihafa, A., Takendu, W. \& Lamaris, J. (2015) Papustyla pulcherrima. In The IUCN Red List of Threatened Species v. 2015.2. Http://www.iucnredlist.org [accessed 25 June 2015].

Wilson, H.B., Joseph, L.N., Moore, A.L. \& Possingham, H.P.

(2011) When should we save the most endangered species? Ecology Letters, 14, 886-890.

\section{Biographical sketch}

Nathan Whitmore's research interests are sustainable harvesting, population modelling, and incorporation of local knowledge in conservation planning. 